\title{
Research on Theoretically Modelling and Quantitatively Calculating Stray Current Corrosion in a Subway System
}

\author{
Zhichao Cai ${ }^{*}$ Xianwei Zhang, Jing Zhang \\ School of Electrical and Automation Engineering, East China Jiaotong University, Nanchang 330013, \\ China; \\ *E-mail: czchebut@foxmail.com
}

doi: $10.20964 / 2020.07 .39$

Received: 6 October 2019 / Accepted: 30 March 2020 / Published: 10 June 2020

\begin{abstract}
To investigate the effect of stray current in subways on the corrosion of buried pipelines near tracks, a 3D-finite element method (FEM) model of stray current distribution for one subway interval was established. Under the operation conditions of subway vehicles, the stray current distribution in the area and its interference with a buried pipeline were analysed and discussed. The calculation found that the area of the buried pipeline corrosion area (anodic area) changed depending on the subway vehicle mode of operation. Corrosion predictions of buried metals with different burial depths were carried out to simulate the corrosion rules of metal anodes under a DC stray current environment. A metal mass loss analysis shows that the mass loss of the metal due to corrosion is inversely proportional to the buried depth of the metal specimen. The established proportional experimental FEM model accurately verified the experimental results. Stray current corrosion modelling and quantitative calculation methods can provide important technical guidance for the health assessment of buried metal corrosion.
\end{abstract}

Keywords: stray current, FEM, corrosion, quantitative calculation

\section{FULL TEXT}

(C) 2020 The Authors. Published by ESG (www.electrochemsci.org). This article is an open access article distributed under the terms and conditions of the Creative Commons Attribution license (http://creativecommons.org/licenses/by/4.0/). 